Tamil Nadu, India

kamala.thiagarajan@gmail.com Cite this as: BMJ 2021;373:n1564 http://dx.doi.org/10.1136/bmj.n1564 Published: 25 June 2021

\section{How to fix India's depleted rural workforce}

\section{The tragedies of India's second wave of covid-19 have exposed the entrenched inequalities between urban and rural areas, not least in the healthcare workforce, writes Kamala Thiagarajan}

\section{Kamala Thiagarajan freelance journalist}

As India continues to struggle with covid-19, the pandemic has laid bare many of the severe vulnerabilities in its healthcare. Particularly concerning are the areas bereft of specialised health services, blood banks, and critical care-so called "medical deserts," which are mostly in rural areas.

More than half of the world's population lives in a rural area, according to the United Nations Department of Economic and Social Affairs. Projections suggest that by 2050, that will increase to $68 \%$-one in three people globally. In India, $70 \%$ of its 1.3 billion population lives in a rural area. However, around $80 \%$ of the country's 1.14 million registered doctors work in cities. ${ }^{1}$

India also has a nationwide shortage of doctors, with one for every 11082 of the population; the World Health Organization recommended ratio is 1:100o. ${ }^{2}$ The country is estimated to be missing around 600 ooo doctors and two million nurses to meet WHO levels, ${ }^{3}$ and the problem is particularly acute in less attractive rural areas.

Primary healthcare centres are considered the backbone of India's rural health systems-they cater for 20000 to 30000 people each and carry most of the patient load in rural areas. However, Gagandeep Kang, professor of gastrointestinal sciences at the Christian Medical College, Vellore, says primary healthcare centres are not adequately equipped to provide critical care during emergencies, such as snake bite, poisoning, or other trauma.

Larger, community health centres are fewer, but as 30 bed hospitals they are designed to provide some specialist care. (India also has a hospital bed shortage, and rural India has roughly three government hospital beds per 10 ooo people, ${ }^{4}$ compared with nearly 12 in urban India ${ }^{5}$ ). Each community health centre is supposed to be staffed by a surgeon, a physician, an obstetrician or gynaecologist, and a paediatrician.

However, a 2019 report on rural health statistics by the government think tank NITI Aayog found that, for community health centres in rural areas, only $15 \%$ of the surgical posts, $13 \%$ of the physician posts, $25 \%$ of the obstetrics and gynaecology posts, and $20 \%$ of the paediatrician posts were filled. ${ }^{6}$

The government has proposed some solutions, such as allowing Ayurvedic doctors to perform some surgical procedures-a move the Indian Medical Association opposed through India's Supreme Court-or setting up a separate bachelor of rural medicine qualification. ${ }^{7}$ Kang says these solutions are far from practical in the long term. "You need a career path for these positions and right now, we don't have that," she says. "Instead, we need a systemic fix in human resources."

\section{Centralised training: a shot in the foot}

On 6 May, WHO released a report analysing medical deserts globally and setting out guidelines for ways countries could strengthen public health systems in remote areas to avoid the growing gap between urban and rural locations. ${ }^{8}$

The report referenced two observational studies which found that students given more hands-on training and greater exposure to rural patients (and their differing health issues) did better in clinical examinations when compared with their urban based counterparts (rural areas generally see higher rates of chronic disease than cities). The studies also found that the longer the exposure to rural training, the stronger a student's intention to practise in rural areas.

However, most of India's medical colleges are based in cities, ${ }^{9}$ so exposure and familiarity with rural clinical settings is often lacking.

At Kang's college, during their community medical posting in the first year, medical students are expected to live in a village for a couple of weeks, designing public health programmes and understanding the reality of healthcare in a rural area. "Our students tend to be much more grounded in community [welfare]," she says, "After their final year, they have a commitment to serve for two years in a rural area before specialising."

The WHO report advocates enrolling students from diverse rural backgrounds for training in various health disciplines to increase the likelihood of their choosing to practise in rural areas after graduating. Kang told The BMJ that her college used to do this: until 2013, it was able to recruit students from remote areas, training them so that they could go back and serve their own communities.

However, in 2013, the Indian government introduced a nationwide entrance examination for medical and dental colleges. "Fewer students from remote communities can clear the centralised entrance exam now that it's purely merit-based. So these areas will see fewer doctors," says Kang. "Our ability to send doctors to places that need them most has been, in some way, a casualty of this centralised selection process. The best students don't necessarily make the best doctors."

\section{Incentives}

Several Indian states are now taking measures. Maharashtra in the west and Odisha in the north east, 
for instance, are offering higher salaries and other financial incentives to doctors who agree to practise in remote rural areas. ${ }^{10}$

Since 2017, the government has suggested that medical colleges make rural practice a standard part of clinical training. ${ }^{11}$ This has been attempted by government aided medical colleges in over a dozen Indian states, such as Delhi, Karnataka, Gujarat, Andhra Pradesh, Goa, Himachal Pradesh, Kerala, Maharashtra, Odisha, Rajasthan, Tamil Nadu, Telangana, West Bengal.

However, students don't always comply, particularly in those places where it is not mandatory. Between 2018 and 2020, 85\% of medical graduates in the north Indian state of Gujarat shirked the rule, preferring to pay hefty fines of up to Rs2m (£19 344; €22 599; \$26 998), rather than take the posting. ${ }^{12}$

In March, a parliamentary committee proposed a bill that makes rural service mandatory for three years, suggesting that those who violate it lose their licence to practise. ${ }^{13}$ But so far the state of Karnataka remains the only one that has made a one year rural posting mandatory for all its 7000 medical college graduates. ${ }^{14}$

Chandrakant Lahariya, an epidemiologist who's worked with WHO India, says forcing students and medical schools to comply with the rules won't work. Like Kang, he points to the need for "career growth and a work environment where a government run hospital can retain a healthy workforce."

This is echoed by WHO: working in an environment that embraces recognition and appreciation by colleagues or the community was listed as one of the most important reasons given for why workers surveyed stayed in a rural area (the reason was listed in 14 of 20 studies the WHO report reviewed).

In Ghana, for instance, a voluntary community health worker programme, with biweekly supportive supervision, cordial working relationships among health workers, and recognition of the efforts of rural health workers, had a drop-out rate of $21.2 \%$ over 30 months, compared with 50\% over 24 months in the other regional programmes in Nigeria and 33\% over 11 months in Kenya.

\section{Thinking broadly}

The workforce problem is not just doctors (box 1). Better training for healthcare staff generally can ensure health facilities are functional and provide more support systems, says Lahariya. "We need a team based approach to healthcare. When a doctor is not supported by sufficient paramedical and nursing staff, it leads to frustration.”

\section{Box 1: Volunteer workers plugging the gaps in the pandemic}

Because of the shortage of nurses, India's public healthcare system relies heavily on volunteers, known as Aganwadi workers, and accredited social health activists (ASHA) workers, a force of 900000 women trained to encourage people in their rural communities to vaccinate, to seek out hospitals for institutionalised childbirth, and to ensure that women have access to contraceptives.

ASHA workers are employed on commission, based on the number of people they mobilise to hospitals and health centres. Across the country they have protested over poor pay and unpaid wages and having no fixed salary.

During the pandemic, ASHA workers across India have also been expected to keep track of covid positive people in their communities and to urge them to come for testing. This put the workers themselves at risk, both of infection and of facing the wrath of covid positive patients. When ASHA workers asked for appropriate personal protective equipment at the start of the pandemic, they were threatened with dismissal.

"Their role was mobilisation, but now they're expected to participate in programmes that are not appropriate to their training," says Kang.
Lahariya says governments have to think more broadly if they are truly to tackle the gaps in the workforce. "To attract and retain talent, it would mean creating better schools for children and provisions for families in the long run," Lahariya says.

Weaker healthcare in remote areas was already inextricably linked to the lack of passable roads even before the pandemic. ${ }^{15}$ "At the heart of this problem in India are issues with access, connectivity, and [proper] health governance," says Kang. "Even when a remote area has a government run hospital, it is staffed and functional only for part of the time," she says. If you need care outside of these daytime hours, there is little choice than to travel further or pay for private healthcare.

The result is either large bills or a long journey accompanied by loss of income through missing work. "It's worse for patients who are sick and immobile, for pregnant women, and in tribal areas where health penetration is less," says Kang. "Instead of providing care when it is needed, we are providing it when it is convenient [for doctors and not for the patient]."

Competing interests: I have read and understood the BMJ policy on declaration of interests and have no relevant interests to declare.

Commissioning and peer review: Commissioned; not externally peer reviewed

Vij D. Health care infrastructure in India: Need for reallocation and regulation. Int J Multidisciplin 2019:4. https://www.researchgate.net/publication/342170461_Health_Infrastructure_in_India_Need_for_Reallocation_and_Regulation\#: :text=Around\%2080\%25\%20of\%20India's1,31\%25\%20of\%20the\%20country's\%20population.

2 Watts K. India's shortage of specialist doctors is still staggering. Health Issues India 2019 Jul 2. https://www.healthissuesindia.com/2019/07/02/indias-shortage-of-specialist-doctors-is-stillstaggering.

3 India facing shortage of 600000 doctors, 2 million nurses: Study. The Economic Times 2019 Apr 14. https://economictimes.indiatimes.com/industry/healthcare/biotech/healthcare/india-facing shortage-of-600000-doctors-2-million-nurses-study/arti-

cleshow/68875822.cms?utm_source=contentofinterest\&utm_medium=text\&utm_campaign=cppst.

4 Kumar A, Nayar KR, Koya SF. COVID-19: Challenges and its consequences for rural health care in India. Public Health in Practice 2020;1:100009. doi: 10.1016/j.puhip.2020.100009

5 Mampatta SP. Rural India vs covid-19: Train curbs a relief but challenges remain. Business Standard 2020 Mar 23 https://www.business-standard.com/article/economy-policy/rural-india-vs-covid19-train-curbs-a-relief-but-challenges-remain-120032300007_1.html.

6 Government of India Ministry of Health and Family Welfare Statistics Division. Rural health statistics. 2018-19. https://main.mohfw.gov.in/sites/default/files/Final\%20RHS\%202018-19_0.pdf. Garg S, Singh R, Grover M. Bachelor of rural health care: do we need another cadre of health practitioners for rural areas? Natl Med I India 2011;24:35-7.pmid: 21608358

8 World Health Organization. WHO guideline on health workforce development, attraction, recruitment and retention in rural and remote areas. WHO 2021; 6 May. https://www.who.int/publications/i/item/9789240024229.

9 Sabde Y, Diwan V, Mahadik VK, Negandhi H, Trushna T, Zodpey S. Medical schools in India: pattern of establishment and impact on public health-a Geographic Information System (GIS) based exploratory study. BMC Public Health 2020;20:755. doi: 10.1186/s12889-020-08797-0 pmid: 32448195

10 What gets docs to villages: Double pay, cheaper edu, salary cut, fines. Times oflndia 2019 Mar 18. https://timesofindia.indiatimes.com/articleshow/68461264.cms?utm_source=contentofinter est\&utm_medium=text\&utm_campaign=cppst.

11 Dharmadhikari S, Dubey S, Zadey S. Why bonded service for doctors has seen only limited success. The Wire. https://science.thewire.in/health/why-bonded-service-for-doctors-has-seenonly-limited-success.

12 Press Trust of India. 85 per cent MBBS graduates avoided rural service in Gujarat in two years. Hindustan Times. 3 Mar. https://www.hindustantimes.com/education/85-per-cent-mbbs-graduates-avoided-rural-service-in-gujarat-in-two-years/story-ALoMzOjDthXOFnZm22ovck.html.

13 Parliament of India. One hundred and twenty-sixth report on demands for grants 2021-22 (demand no 44) of the Department of Health and Family Welfare (Ministry of Health and Family Welfare). 8 March 2021 https://rajyasabha.nic.in/rsnew/Committee_site/Committee_File/ReportFile/14/142/126_2021_3_11.pdf.

14 One year rural service now mandatory for all mbbs graduates in Karnataka. Medical Dialogues 2021 Feb 26. https://medicaldialogues.in/state-news/karnataka/one-year-rural-service-nowmandatory-for-all-mbbs-graduates-in-karnataka-74974.

15 Syed ST, Gerber BS, Sharp LK. Traveling towards disease: transportation barriers to health care access. J Community Health2013;38:976-93. doi: 10.1007/s10900-013-9681-1. pmid: 23543372 